\title{
The Effects of Sustained Inspiration and Expiration on Heart Rate to Elucidate the Physical Mechanics of Respiratory Sinus Arrhythmia
}

\author{
Melvin F Simoyi*, Brenda Martinez and Estefania Jimenez Lopez \\ Department of Biology, College of Arts \& Sciences, Heritage University, USA
}

*Corresponding author: Melvin F Simoyi, Department of Biology, College of Arts \& Sciences, Heritage University, USA

\begin{tabular}{|c|c|}
\hline ARTICLE INFO & ABSTRACT \\
\hline & This study investigated the physical effects of the respiratory cycle on heart rate by \\
\hline Published: 慧 October 24, 2019 & exaggerating the conditions under which Respiratory Sinus Arrhythmia (RSA) occurs. \\
\hline $\begin{array}{l}\text { Citation: Melvin F Simoyi, Brenda Martin- } \\
\text { ez, Estefania Jimenez Lopez. The Effects } \\
\text { of Sustained Inspiration and Expiration } \\
\text { on Heart Rate to Elucidate the Physical } \\
\text { Mechanics of Respiratory Sinus Arrhyth- } \\
\text { mia. Biomed J Sci \& Tech Res 22(2)-2019. } \\
\text { BJSTR. MS.ID.003732. }\end{array}$ & $\begin{array}{l}\text { and consequently heart rate. Four healthy subjects, } 2 \text { male and } 2 \text { females ranging in age } \\
\text { from } 22 \text { to } 43 \text { took maximum inspiration, held it for } 15 \text { seconds and maximum expiration } \\
\text { and held for similar time while breathing through a spirometer flow head. Each } \\
\text { treatment was repeated over } 5 \text { different days with } 5 \text { replicates each time on each subject } \\
\text { and Heart Rate (HR) was monitored through a plethysmograph placed on the volar } \\
\text { surface of the subject's middle finger. There was a significant difference in the longest } \\
\text { RR interval during normal breathing versus the longest RR interval during expire-hold } \\
\text { or inspire-hold treatments; } P \text { values ranged from } P<0.05 \text { to } P<0.0000001 \text {. A significant }\end{array}$ \\
\hline $\begin{array}{l}\text { Keywords: Heart Rate; RR Interval; } \\
\text { Respiratory Sinus Arrhythmia; Maximum } \\
\text { Inspiration; Maximum Expiration }\end{array}$ & $\begin{array}{l}\text { difference in maximum HR during normal breathing versus maximum HR during expire- } \\
\text { hold or inspire-hold treatments was also observed; } P \text { values ranged from } \mathrm{P}<0.02 \text { to } \mathrm{P} \\
<0.000001 \text {. During sustained maximum expiration there was a significant decrease in } \\
\text { the RR Interval and thus significant increase in HR, the opposite of what happens during } \\
\text { regular expiration; } P \text { values ranged from } \mathrm{P}<0.05 \text { to } \mathrm{P}<0.0001 \text {. Maximum sustained } \\
\text { inspiration does indeed significantly amplify RSA compared to normal breathing. } \\
\text { However, maximum sustained expiration significantly reversed RSA observed during } \\
\text { normal breathing expiration. }\end{array}$ \\
\hline
\end{tabular}

\section{Introduction}

It is well established that heart rate variability in synchrony with the respiratory cycle, known as Respiratory Sinus Arrhythmia (RSA), is regulated through cardiac vagal control [1-5]. Since RSA is observed among all vertebrates throughout evolution [6], it is indicative that RSA plays an intrinsic physiological role [1]. This has been shown to optimize the exchange of gases in lung alveoli by matching lung perfusion (blood flow to the lungs) with ventilation $[7,8]$. Even with the extensive studies of heart rate variability spanning over more than 30 years not everything concerning RSA is well understood including its physiological origins. However, the importance of heart rate variability is not in question as indicated by the correlation between decreased heart rate variability with higher morbidity and mortality in many conditions such as heart disease and fetal distress [5] and in fact from all conditions including cancer as demonstrated by Dekker and coworkers [9]

The time between 2 adjacent $\mathrm{R}$ waves on an Electrocardiogram's (ECG) QRS complex is referred to as the RR Interval which is the time it takes for one heartbeat to occur is used to calculate Heart Rate (HR). In healthy individuals RSA is demonstrated by shortened RR Intervals (higher HR) during inspiration and longer RR Intervals (lower HR) during expiration [2-10]. This phenomenon, RSA, has largely been shown to be an indicator of or at least is controlled by cardiac vagal tone $[11,12]$. Despite many years of study there are still aspect about RSA that are not well understood which by itself indicates that there are many physiological factors interacting in complex ways that influence RSA. 
During inspiration thoracic pressure decreases below atmospheric pressure and air rushes into the lungs and the opposite happens during expiration so that air is forced out of the lungs. When thoracic pressure falls below atmospheric pressure by $5 \mathrm{~mm}$ $\mathrm{Hg}$ during inspiration a pressure gradient between veins in the lower limbs subject to atmospheric pressure and the thoracic inferior vena cava exists which facilitates venous return to the right atrium of the heart, a phenomenon dubbed the 'respiratory pump' [13]. By virtue of the location of the heart in the thoracic cavity, surely the ability of the heart to expand during ventricular filling and contract during ventricular emptying (and thus RR Interval and consequently HR) must be subject to the alternating sub-atmospheric pressure (during inspiration) and supra-atmospheric pressure (during expiration). Therefore, the focus of our study is to investigate if indeed HR increases during inspiration when the heart is exposed to sub-atmospheric pressure and decreases during expiration when the heart is exposed to supra-atmospheric pressure.

\section{Hypothesis 1: Inspiration}

During maximum inspiration the pressure in the thoracic cavity is at its lowest sub-atmospheric level and therefore exerts much less compression around the heart resulting in shorter RR intervals and thus faster heart rate.

\section{Hypothesis 2: Expiration}

During maximum expiration the pressure in the thoracic cavity is at its highest supra-atmospheric level and therefore exerts much more compression around the heart resulting in longer RR intervals and thus slower heart rate.

\section{Materials and Methods}

\section{Subjects}

Four subjects, 2 male and 2 females ranging in age from 22 to 43 participated in this study. All 4 subjects were healthy, on normal regular diets, engaged in physical activity from 2 to 7 times per week, used alcohol occasionally on social events, and only 1 male subject smoked the occasional cigar while the other 3 were non-smoking. None of the subjects used recreational drugs and their Body Mass Indices (BMI) ranged from 20.5 to 31.9. The BMI of 3 subjects was below 25 while that of the remaining one subject was above 30 .

\section{Equipment and Setup}

The I Worx Teaching Assistant (IXTA) data acquisition unit was connected to a personal computer using a USB cable after the unit was connected to a power outlet and switched on. The A-FH300L spirometer flow-head was also connected to the IXTA data acquisition device together with the plethysmograph-104 (PT-104). Disposable mouthpieces were used to cover the flow-head for each subject. The LabScribe 3 software which was pre-installed on the personal computer was used to operate the IXTA data acquisition unit.

\section{Procedure}

Subjects were instructed to sit still and quietly and were given time to get accustomed to breathing normally through the flow-head before experimental trials were performed. The plethysmograph was placed on the volar surface of the subject's middle finger. Before starting each experiment trials, the flow-head was calibrated to zero airflow by placing the flow-head with the mouthpiece attached laterally at the level of the mouth to prevent any air from the nose or mouth entering the flow-head. This position was held for 15 seconds before the subject was asked to begin breathing normally through the flow-head for at least $8-10$ breaths.

\section{Maximum Inspiration}

After 8 - 10 breaths through the spirometer flow-head, the subject inspired deeply until inspiratory capacity (IC) was attained and held their breath for 10 seconds. After holding their breath for 15 seconds the subject expired the total IC volume and resumed breathing normally for another $8-10$ breaths before stopping. This procedure was repeated 5 times on different days so that 5 trials were recorded for each subject on each day over the 5 days.

\section{Maximum Expiration}

After 8 - 10 breaths through the spirometer flow-head, the subject expired maximally until only residual volume (RV) remained in the lungs and held their breath for 15 seconds. After holding their breath for 15 seconds the subject inspired the total expired volume (tidal volume + expiratory reserve volume) and resumed breathing normally for another $8-10$ breaths before stopping. This procedure was repeated 5 times on different days so that 5 trials were recorded for each subject on each day over the 5 days.

\section{Data Analyses}

The display time on the multi-channel (Pulse, Airflow, Lung Volumes, and HR tracings) display was adjusted so that the Lung Volume tracing included a segment of 3-5 cycles of normal breathing, the whole 15-second segment of Inspire-Hold/ExpireHold treatment, and 3-5 cycles of normal breathing after the treatment segment as shown in Figure 4.

The top 2 RR Intervals (Pulse channel) and the corresponding HR (Heart Rate channel) were recorded for the normal breathing segment and Inspire-Hold/Expire-Hold treatment segment to determine the maximum effect on these variables for each trial.

The Minimum, Maximum, and Mean HR over 15 seconds of the normal breathing segment and 15 seconds of the Inspire-Hold/ Expire-Hold treatment segment were recorded for each trial. The values for the variables were taken from the Heart Rate channel.

\section{Statistical Analysis}

The experiment was performed on 4 subjects with 5 trials ran for each of the 5 replicates which were done on different days. A single factor analysis of variance (ANOVA) was used to analyze these 
data statistically. Single factor ANOVA was used to perform a simple analysis of variance on data for the 4 subjects in this experiment. The analysis provided a test of the hypothesis that each sample is drawn from the same underlying probability distribution against the alternative hypothesis that underlying probability distributions are not the same for all samples.

Even though the sample size is $n=4$ on each in 1 of the 5 trials for each experimental group, the lowest reading for normal breathing and the highest reading for normal breathing for RR interval and for HR were taken as was the case for the expirehold and the inspire-hold treatment groups. Thus, for each trial 4 data points ( $2 \mathrm{RR}$ interval data points $+2 \mathrm{HR}$ data points) for normal breathing (control) were compared to 4 data points for the treatment groups (2 RR interval data points +2 HR data points). A total of 8 data points for each trial multiplied by 5 trials a day equals 40 data points multiplied by 5 replicates equals 200 data points per subject per treatment group compared statistically. The grand total of data points compared statistically for this experiment is 200 data points per subject per treatment group multiplied by 4 subjects equals 800 data points multiplied by 4 experimental groups ( 1 normal breathing vs. expire-hold and 1 normal breathing vs. inspire-hold) equals 3,200 data points compared statistically.

\section{Discussion}

Figures 1,4,7,10,13,16,19 and 22 depict the pulse (Electrocardiogram [ECG] tracing), air flow, lung volumes, and heart rate as displayed on the IXTA Main window during the Inspire-Hold treatments and during the Expire-Hold treatments for all 4 subjects who participated in this study. Each of the 4 channels i.e. pulse, air flow, lung volumes, and heart rate in all these figures show very clear and clean tracings of each respective activity being recorded in each channel which is indicative of subjects who were well trained to relax and breath normally through the spirometer flow-head and to perform the maximum inspiration and hold treatment as well as the maximum expiration and hold treatment. This is important in order to obtain data that are consistent among the 4 subjects. It minimizes variability between subjects that is due to differences among subjects in performing the activities within the treatments in the study thereby isolating the true effects of the treatments being measured.

During normal inspiration and expiration HR does indeed increase and decrease respectively, a phenomenon known as Respiratory Sinus Arrhythmia (RSA), which has been amply demonstrated by many articles [14-16]. In these articles the importance of RSA is underscored by its relationship to a variety of human conditions, diseases, or pathology including the association of RSA as a psychophysiological index of emotional regulation in substance use disorder [14]; the association of RSA as a non-invasive index of 'brainheart' interaction in stress [15]; and RSA as a predictor of restricted repetitive behaviors which are a key diagnostic feature of autism spectrum disorder [16]. It cannot be overstated how critical it is to understand the phenomenon that is RSA.
In this study we wanted to accentuate the conditions under which heart rate increases and decreases during RSA by having subjects maximally expire and inspire then hold breath for 15 seconds. We wanted to determine if the key feature of RSA, variation of HR with respiration i.e. increase during inspiration and decrease during expiration, is in fact also accentuated when the conditions under which RSA occurs are accentuated or exaggerated. Indeed RSA was amplified but only during maximum inspiration (during maximum expiration HR was also increased instead of decreasing as in regular expiration) and this is well demonstrated in Figures 2,5,8,14 and 23 in which a significant difference was observed in the highest RR interval attained across all subjects during normal breathing versus expire-hold and normal breathing versus inspire-hold treatments. $P$ values for this comparison ranged from $\mathrm{P}<0.05$ to $\mathrm{P}<0.0000001$. All Inspire-Hold treatments in all 4 subjects showed a significant decrease when the RR interval was compared to the Normal Breathing RR interval as indicated by $P$ values ranging from $\mathrm{P}<0.05$ to $\mathrm{P}<0.0000001$. Only Figures 11 and 17 did not show a statistically significant decrease when the Expire-Hold RR interval was compared to the Normal Breathing RR interval; $\mathrm{P}<0.3$ and $\mathrm{P}<0.5$ respectively. This observation may have been due to occasional spikes in the RR interval that occurred in the IXTA data acquisition system even despite that subjects performed experimental procedures relatively well. The ExpireHold treatments could have been prone to these spikes probably because it is more uncomfortable to hold one's breath after maximum expiration compared to holding breath after maximum inspiration even in well trained subjects.

Because it is not feasible to isolate the physical effects of thoracic pressure on HR; we allowed the participants to maximally inspire or expire then hold their breath for 15 seconds which maximized the effects of low and high thoracic pressure, respectively. Denver et al. [17] questioned estimation of RSA by manipulating respiration frequency but with the multitude of factors influencing HR, manipulation of breathing cycle maybe the only way to determine the effect of respiration on RSA. For a long time, it has been deemed important to correct RSA for respiratory influences [18], yet there has been a paucity of research in this area [19].

Similar effects were observed with heart rate. A comparison in HR during normal breathing versus expire-hold and normal breathing versus inspire-hold treatments demonstrated a significant difference in the maximum HR attained as indicated in Figures 3,6,9,15,21 and 24 where $P$ values ranged from $P<0.02$ to $\mathrm{P}<0.000001$. All Inspire-Hold treatments in all 4 subjects showed a significant increase when the HR was compared to the Normal Breathing $\mathrm{HR}$ as indicated by $P$ values ranging from $\mathrm{P}<0.02$ to $\mathrm{P}$ $<0.000001$. Only (Figures 12 and 18) did not show a statistically significant increase when the Expire-Hold HR was compared to the Normal Breathing HR; $\mathrm{P}<0.7$ and $\mathrm{P}<0.6$ respectively. This observation may have been due to occasional spikes in HR that occurred in the IXTA data acquisition system even despite that 
subjects performed experimental procedures relatively well. The Expire-Hold treatments could have been prone to these spikes probably because it is more uncomfortable to hold one's breath after maximum expiration compared to holding breath after maximum inspiration even in well trained subjects.

Many studies have indicated that the RR Interval is shortened during inspiration (higher HR) and lengthened during expiration (lower HR) [2-19]. By virtue of the location of the heart in the thoracic cavity, surely the ability of the heart to expand during ventricular filling and contract during ventricular emptying (and thus RR Interval and consequently HR) must be subject to the alternating sub-atmospheric pressure (during inspiration) and supra-atmospheric pressure (during expiration). Exaggerating conditions during RSA amplifies this effect as we demonstrated in this study but only during maximum inspiration, during maximum expiration HR also increased instead of decreasing like it normally does during regular expiration.

It is very well established that the sinoatrial node (SA node) is the dominant pacemaker of the heart and regulates the frequency of heartbeat [20] and this was established a very long time ago [21]. Indeed, the sinoatrial node (SA node) sets the heart's beating rhythm and pace but when a person starts intense physical activity, automatically the heart beats faster to provide more blood to the active muscles. However, one does not fail to attribute the faster heart rate to the intense physical activity just because it is the SA node that sets the beating rhythm and pace of the heart. In similar fashion and reasoning we have designed our study to investigate the effects of breathing pattern manipulations on RSA. Bouairi and coworkers [22] stated that RSA in humans and in animals is mediated almost entirely through changes in parasympathetic cardiac vagal tone and this has been reported by many other studies [23-27]. While fully cognizant of the fact that RSA is controlled by cardiac vagal tone, we wanted to investigate what happens to RSA when a person takes maximum inspiration and holds for 15 seconds and similarly when a person expires maximally and holds for 15 seconds. Even though RSA is controlled by cardiac vagal tone, there are physiological and/or physical factors that would influence the brainstem's parasympathetic control of RSA. Indeed, we found that the normal RSA observations where HR increases during inspiration and decreases during expiration were not fully observed in our study in that HR increased significantly during maximum expiration held for 15 seconds. We certainly feel that this is a novel and in fact exciting observation and we have put forward some plausible explanations for this observation.

Our study demonstrated that indeed the RR Interval is significantly shortened during sustained maximum inspiration resulting in higher HR compared to normal breathing RR interval with lower HR. This is in agreement with our first hypothesis about sustained inspiration resulting in shorter RR intervals hence higher HR. However, we did not observe longer RR Intervals during sustained maximum expiration as expected based on our second hypothesis for sustained expiration. In fact, we observed significantly shorter RR Intervals hence higher HR during maximum expiration which was the exact opposite of our second hypothesis. This may be because HR is influenced more by the amount of blood that is returned to the heart following the principles of FrankStarling Law of the heart which states that during systole, the heart pumps out the volume of blood returned to it during diastole [1329] rather than the mere physical mechanics of sub-atmospheric thoracic pressure during inspiration and supra-atmospheric thoracic pressure during expiration directly on the heart itself.

That is, the more stretching that occurs to the myocardium during ventricular filling, the greater the pressure generated by the heart, and thus the greater the stroke volume. Simply put; the heart beats faster when more blood is returned to it as the higher thoracic pressure during maximum expiration compresses the venae cavae and the pulmonary veins causing more blood to be deposited into the atria. Furthermore, this may be a survival mechanism in which the body attempts to provide more 02 to the cells by pumping more blood from the heart during expiration, a time when the body is not taking in more $\mathrm{O}_{2}$. This suggests that during the cardiac cycle there are more urgent matters to be addressed than the mere direct physical mechanics of intra-thoracic pressure on the heart during the respiratory cycle.

Results: (Figures 1-24).

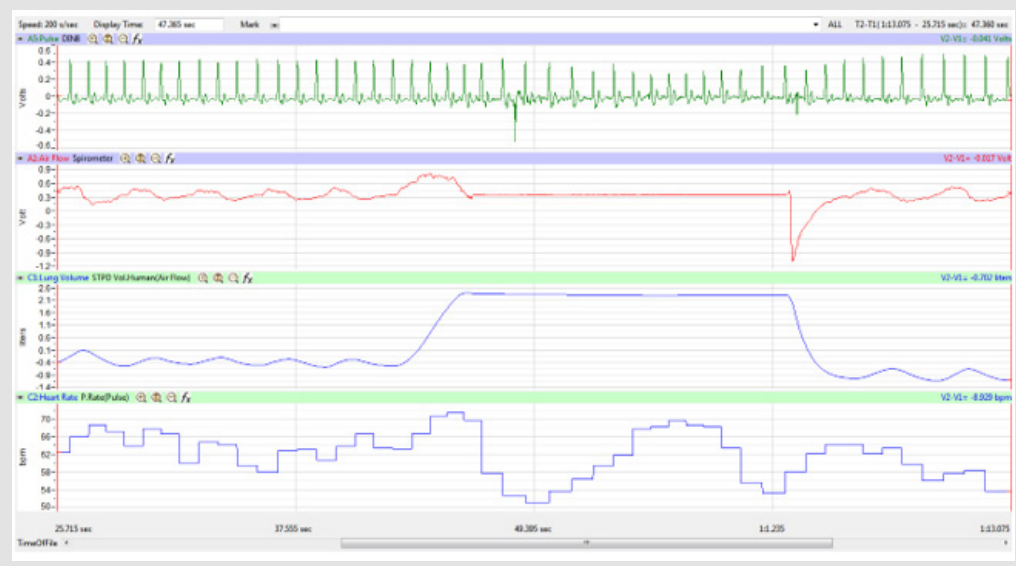

Figure 1: Subject 1 (43 Year-old, Male) - Inspire-Hold Treatment. 


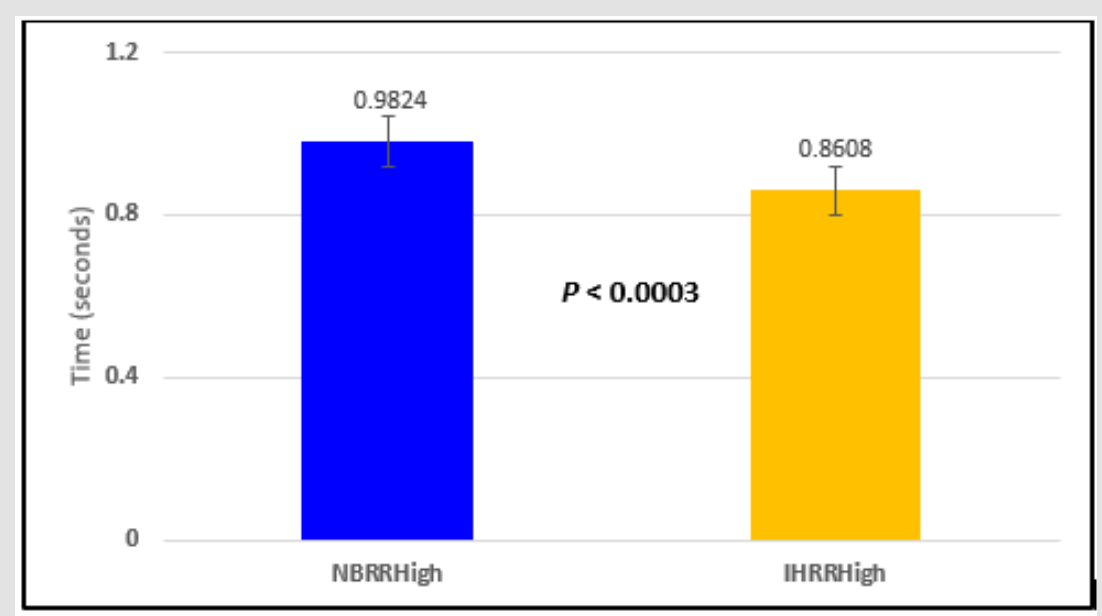

Figure 2: Subject 1 Normal Breathing RR Interval vs. Inspire-Hold RR Interval (NBRRHigh = longest Normal Breathing RR Interval; IHRRHigh = longest Inspire-Hold RR Interval).

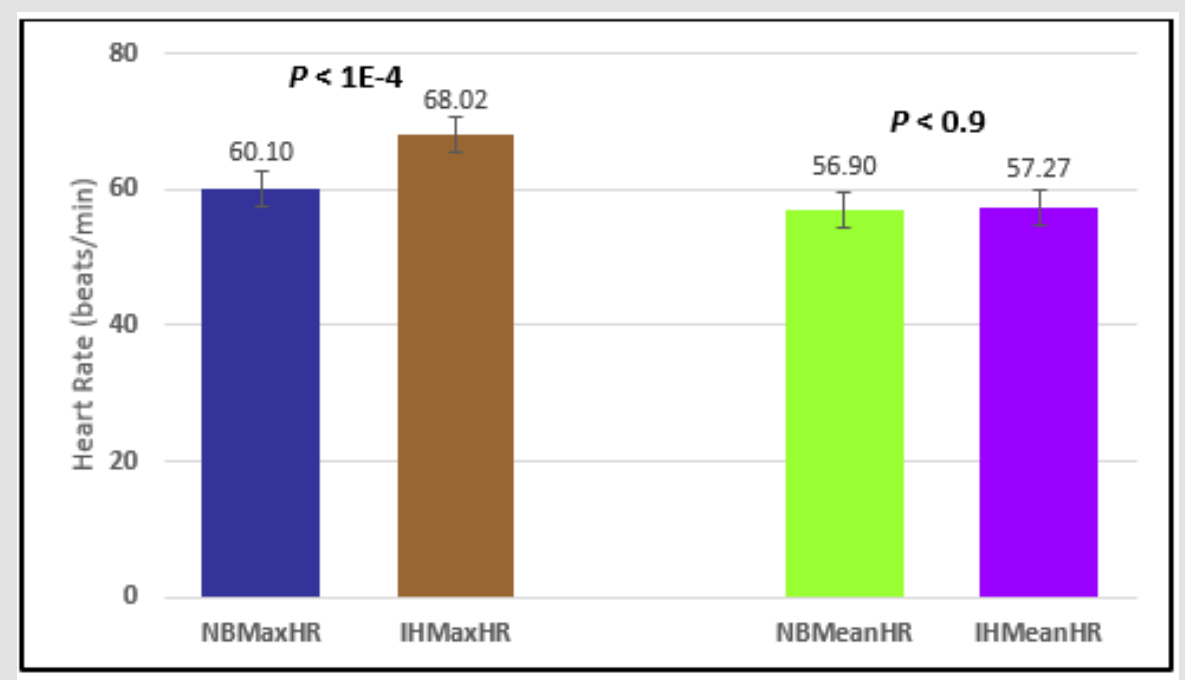

Figure 3: Subject 1 Normal Breathing Heart Rate vs. Inspire-Hold Heart Rate (NBMaxHR = Normal Breathing Maximum Heart Rate; IHMaxHR = Inspire-Hold Maximum Heart Rate; NBMeanHR = Normal Breathing Mean Heart Rate; IHMeanHR = Inspire-Hold Mean Heart Rate).

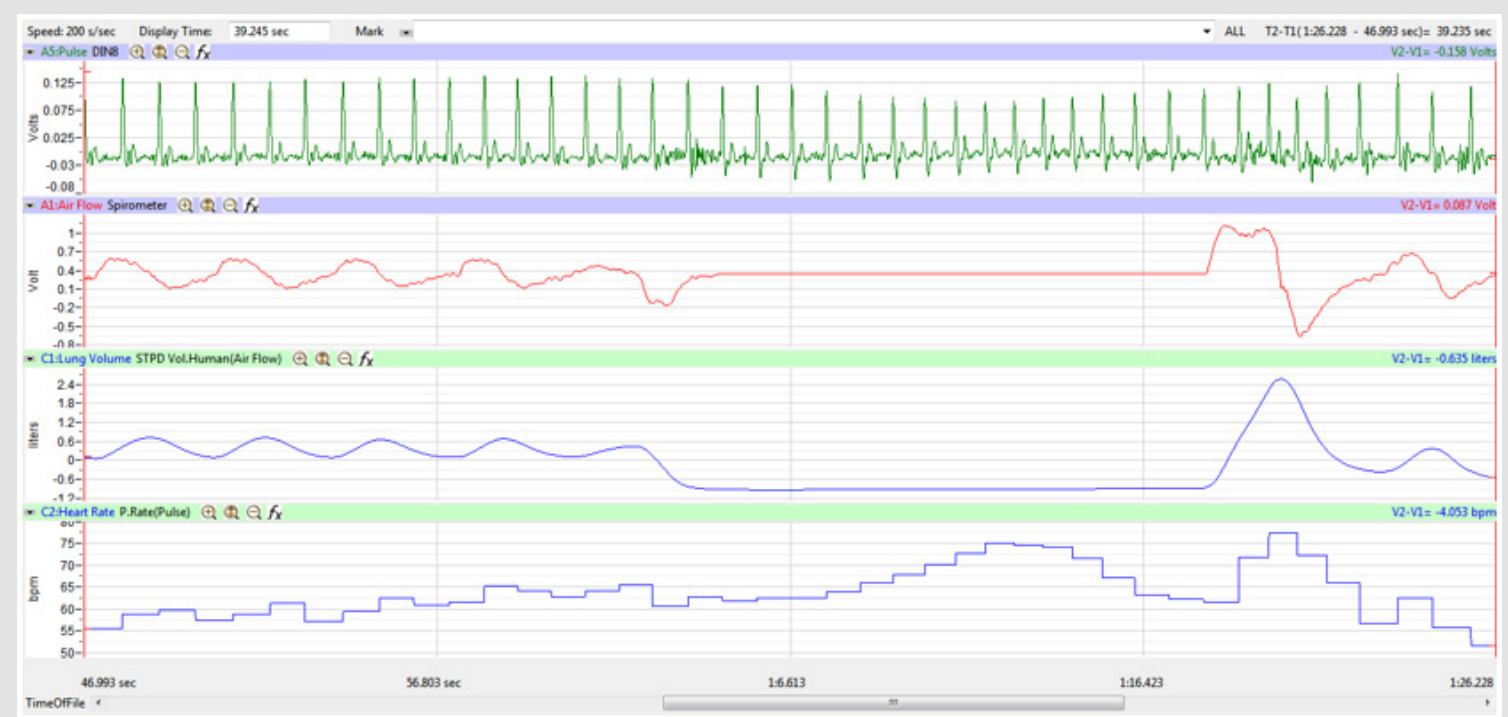

Figure 4: Subject 1 (43 Year-old, Male) - Expire-Hold Treatment. 


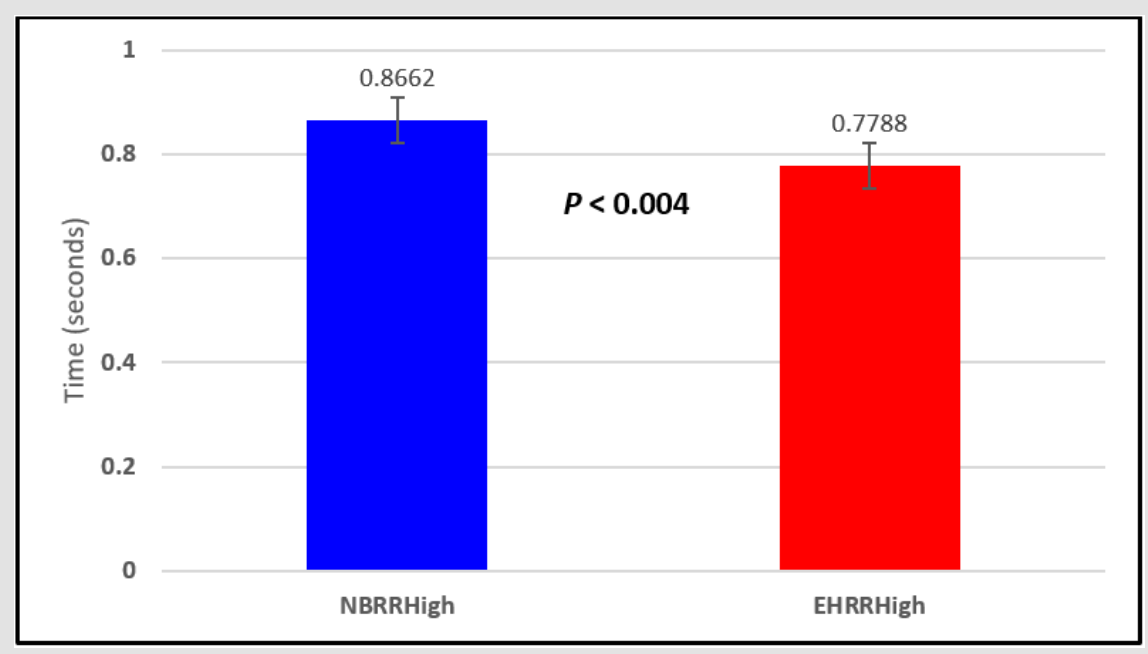

Figure 5: Subject 1 Normal Breathing RR Interval vs. Expire-Hold RR Interval (NBRRHigh = longest Normal Breathing RR Interval; EHRRHigh = longest Expire-Hold RR Interval).

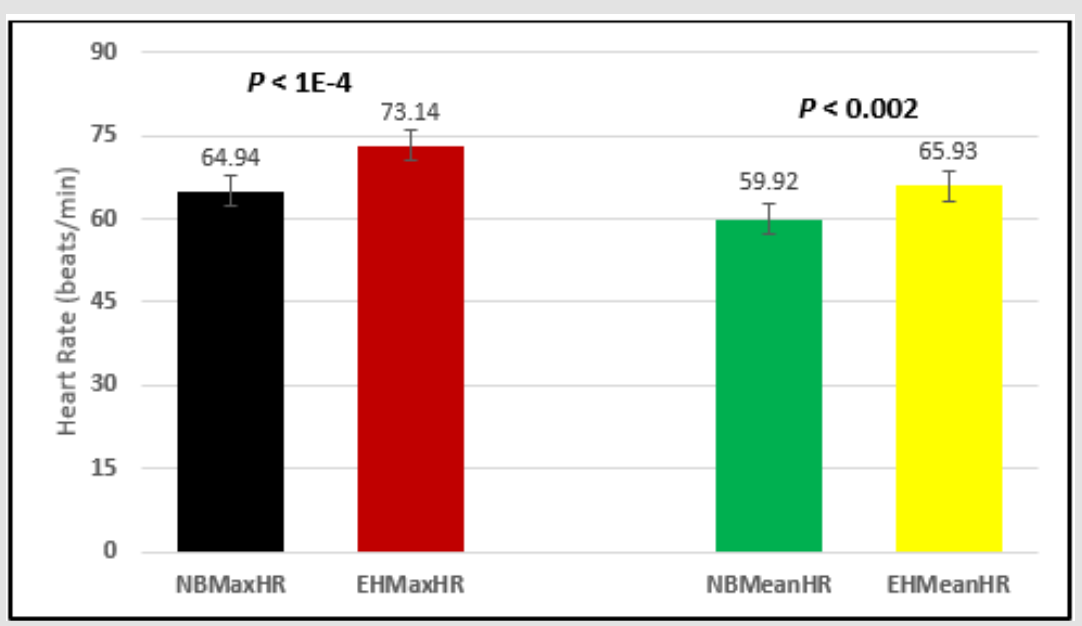

Figure 6: Subject 1 Normal Breathing Heart Rate vs. Expire-Hold Heart Rate (NBMaxHR = Normal Breathing Maximum Heart Rate; EHMaxHR = Expire-Hold Maximum Heart Rate; NBMeanHR = Normal Breathing Mean Heart Rate; EHMeanHR = Expire-Hold Mean Heart Rate).

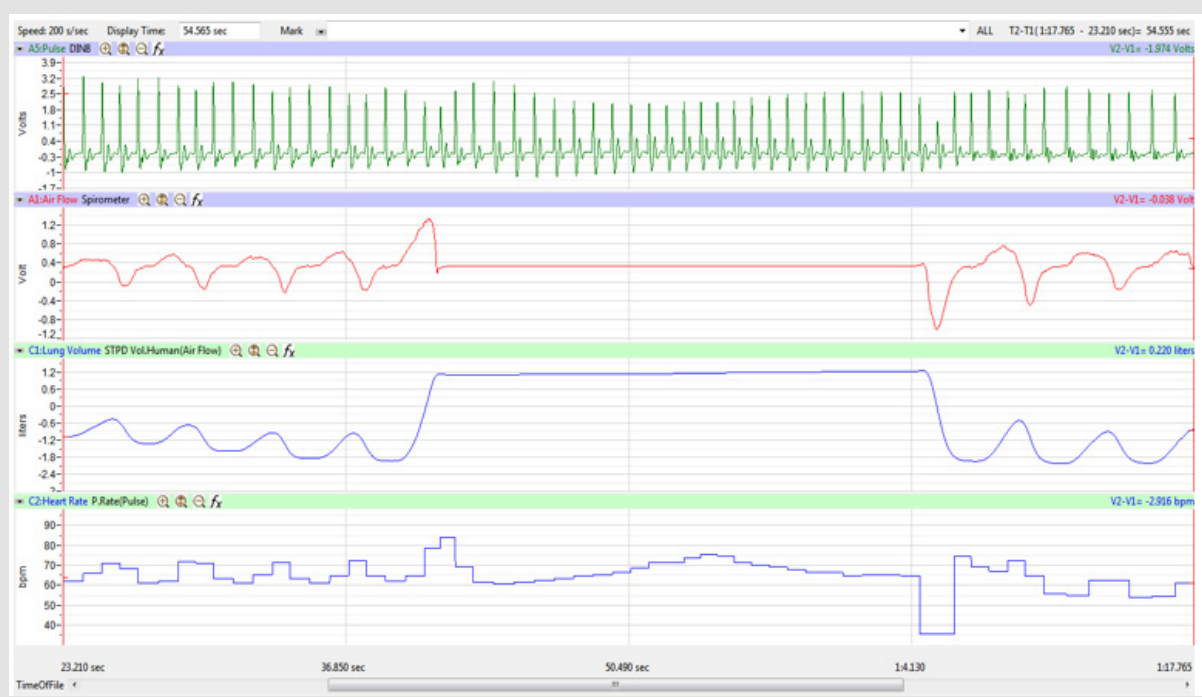

Figure 7: Subject 2 (26 Year-old, Male) - Inspire-Hold Treatment. 


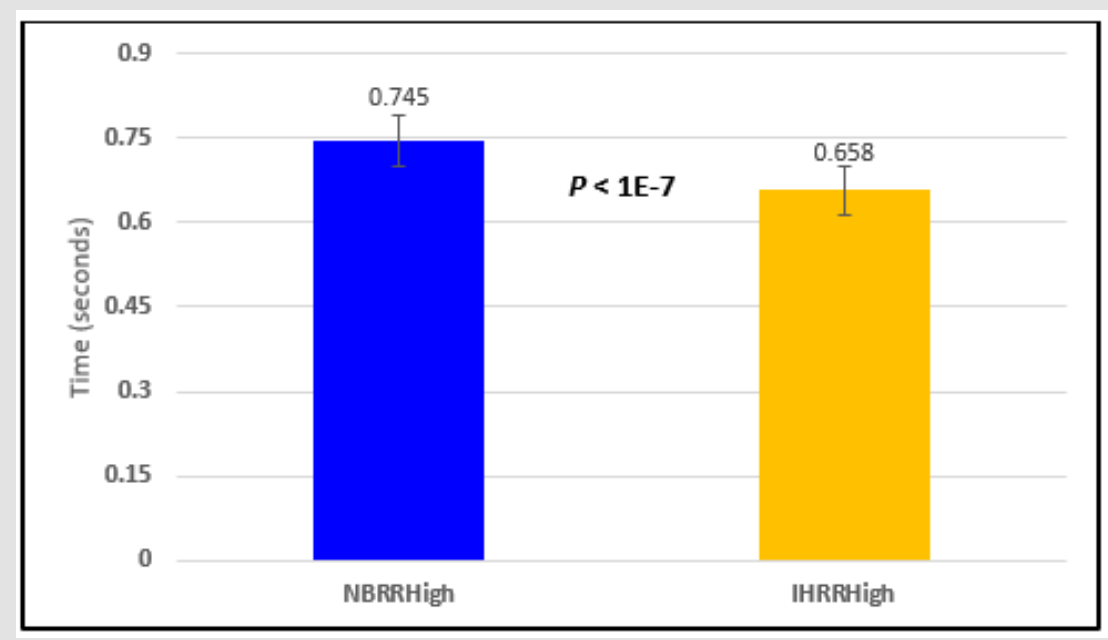

Figure 8: Subject 2 Normal Breathing RR Interval vs. Inspire-Hold RR Interval (NBRRHigh = longest Normal Breathing RR Interval; IHRRHigh = longest Inspire-Hold RR Interval).

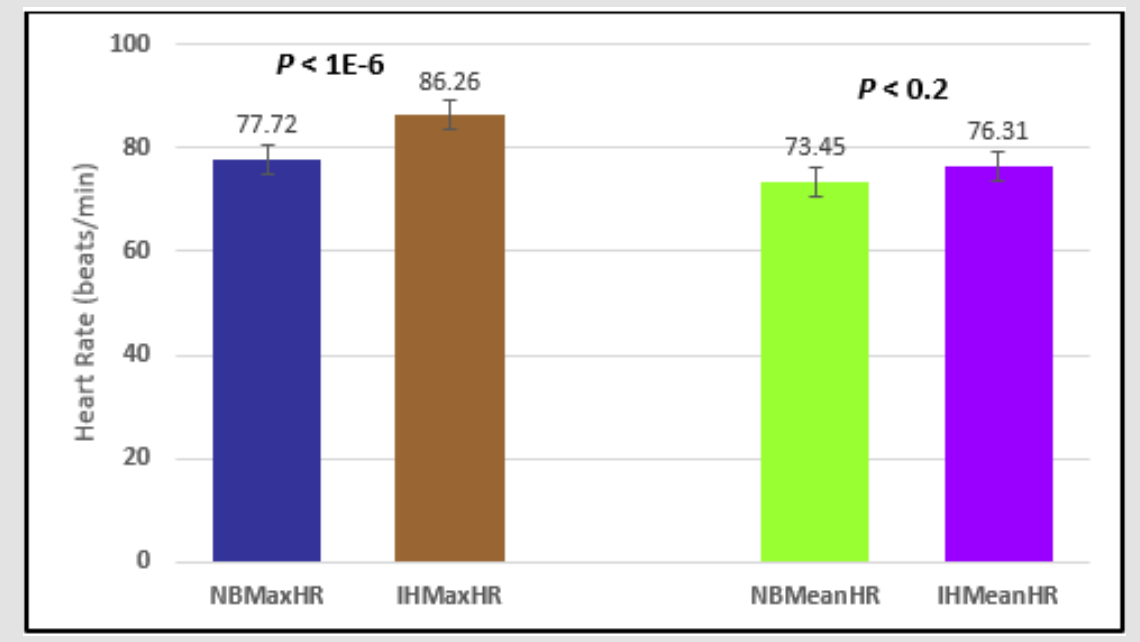

Figure 9: Subject 2 Normal Breathing Heart Rate vs. Inspire-Hold Heart Rate (NBMaxHR = Normal Breathing Maximum Heart Rate; IHMaxHR = Inspire-Hold Maximum Heart Rate; NBMeanHR = Normal Breathing Mean Heart Rate; IHMeanHR = Inspire-Hold Mean Heart Rate).

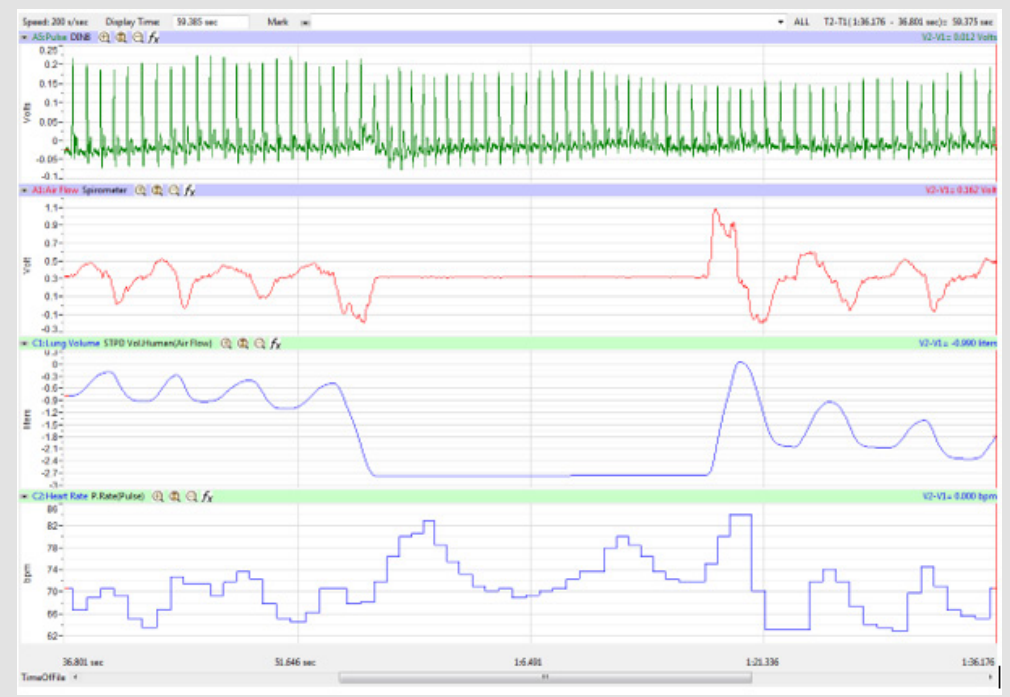

Figure 10: Subject 2 (26 Year-old, Male) - Expire-Hold Treatment. 


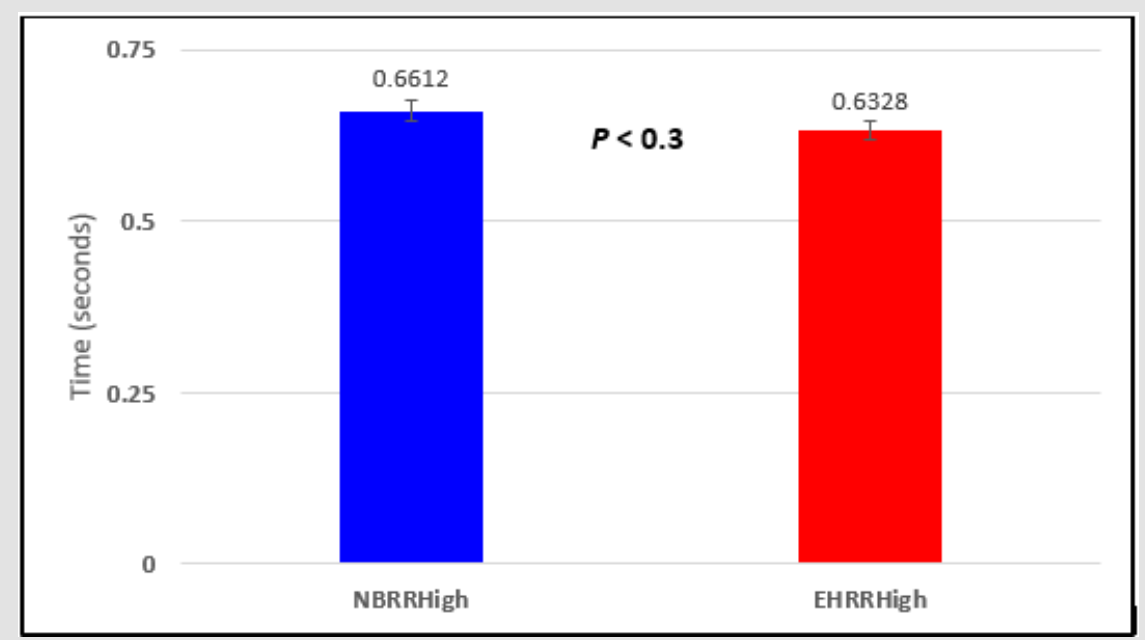

Figure 11: Subject 2 Normal Breathing RR Interval vs. Expire-Hold RR Interval (NBRRHigh = longest Normal Breathing RR Interval; EHRRHigh = longest Expire-Hold RR Interval).

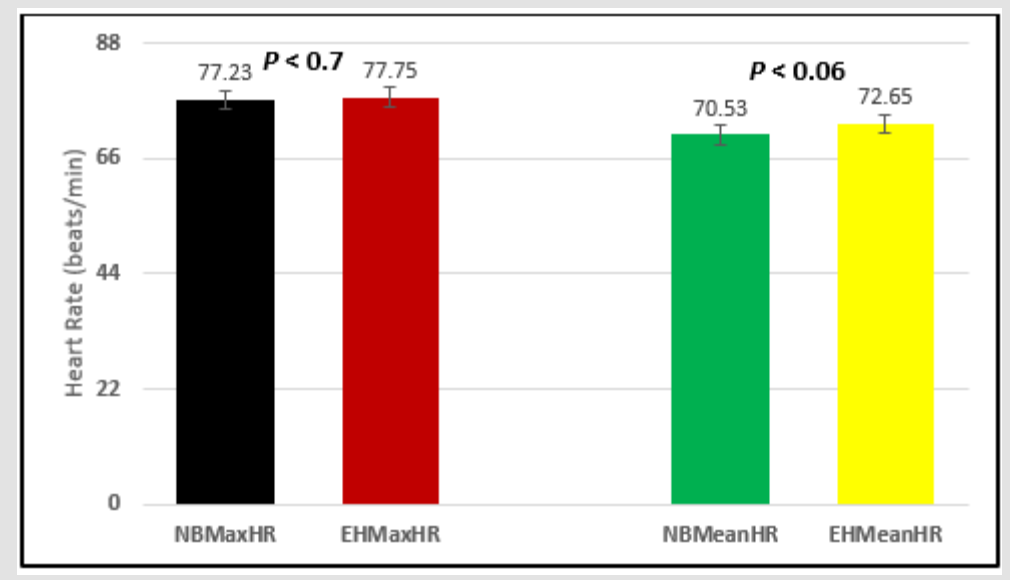

Figure 12: Subject 2 Normal Breathing Heart Rate vs. Expire-Hold Heart Rate (NBMaxHR = Normal Breathing Maximum Heart Rate; EHMaxHR = Expire-Hold Maximum Heart Rate; NBMeanHR = Normal Breathing Mean Heart Rate; EHMeanHR = Expire-Hold Mean Heart Rate).

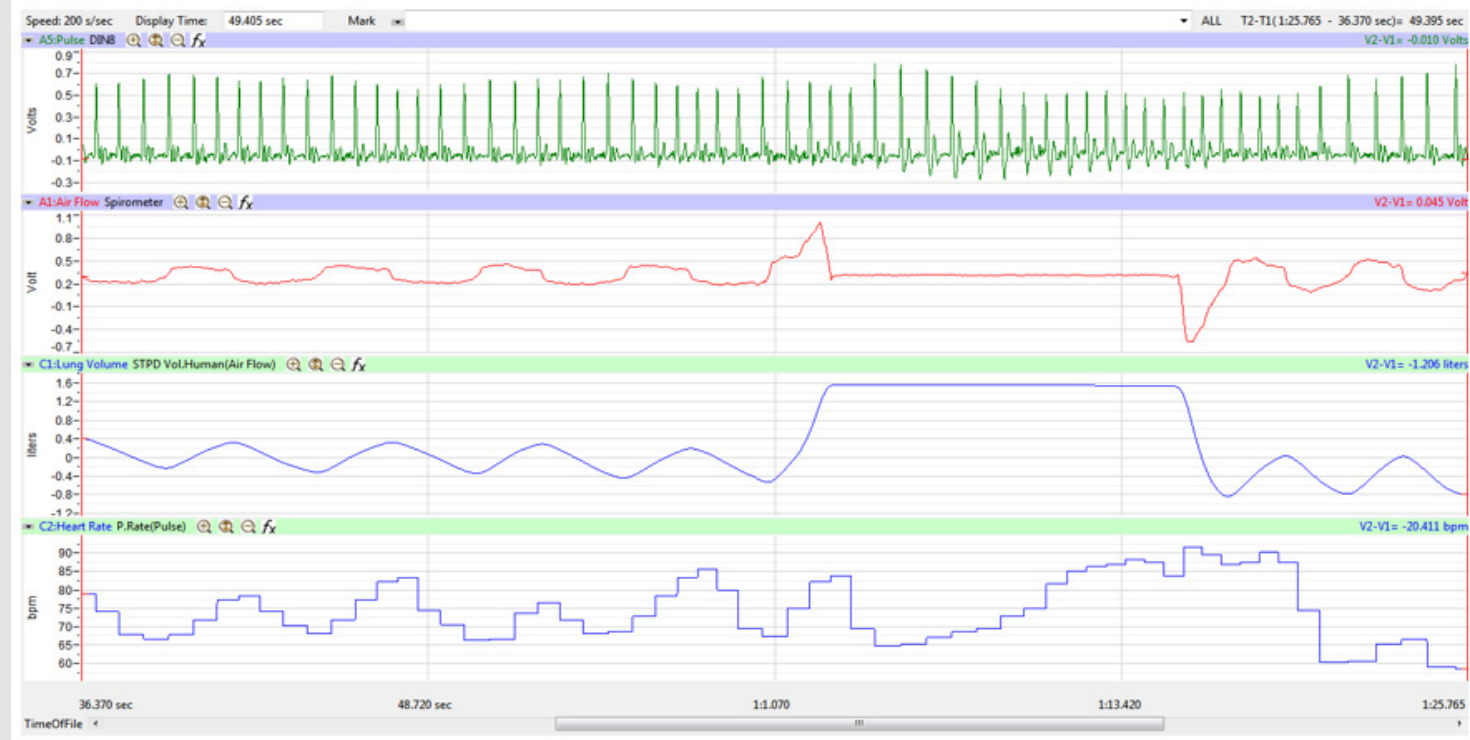

Figure 13: Subject 3 (26 Year-old, Female) - Inspire-Hold Treatment. 


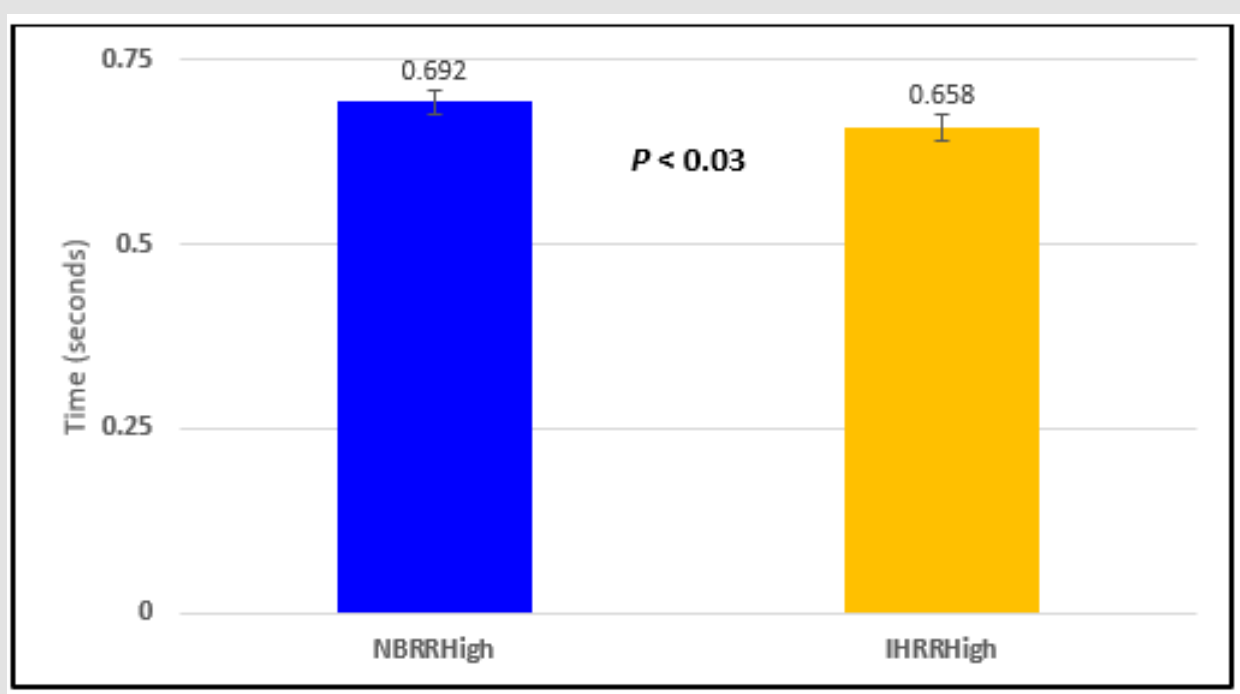

Figure 14: Subject 3 Normal Breathing RR Interval vs. Inspire-Hold RR Interval (NBRRHigh = longest Normal Breathing RR Interval; IHRRHigh = longest Inspire-Hold RR Interval).

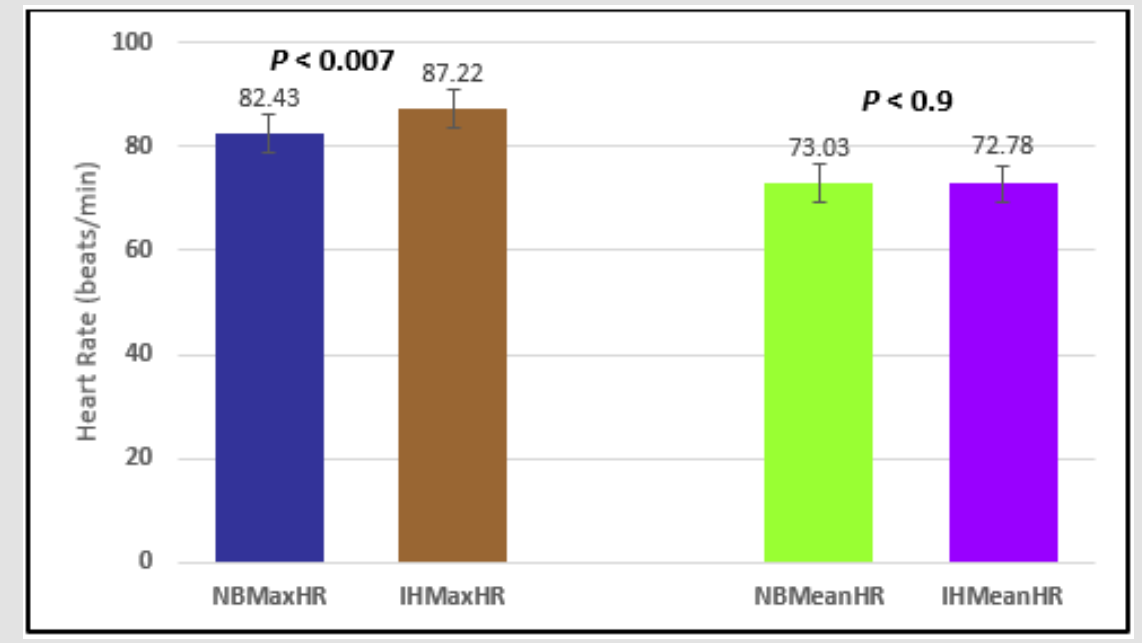

Figure 15: Subject 2 Normal Breathing Heart Rate vs. Expire-Hold Heart Rate (NBMaxHR = Normal Breathing Maximum Heart Rate; EHMaxHR = Expire-Hold Maximum Heart Rate; NBMeanHR = Normal Breathing Mean Heart Rate; EHMeanHR = Expire-Hold Mean Heart Rate).

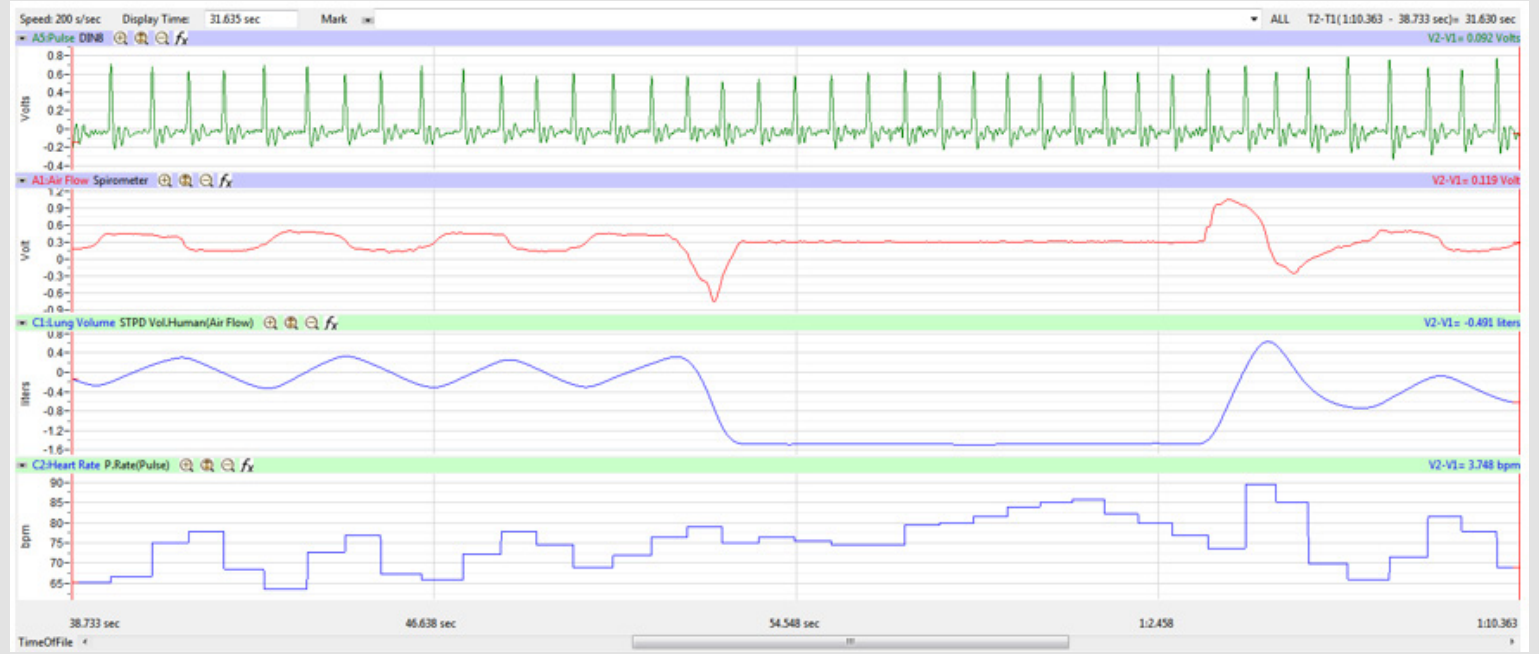

Figure 16: Subject 3 (26 Year-old, Female) - Expire-Hold Treatment. 


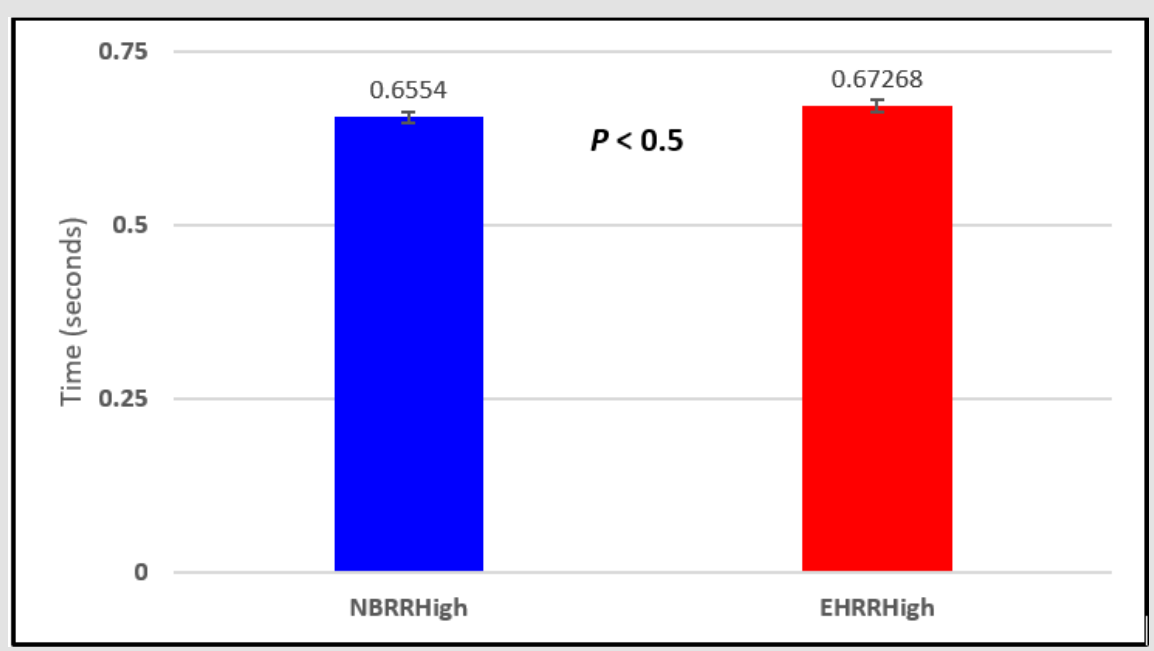

Figure 17: Subject 3 Normal Breathing RR Interval vs. Expire-Hold RR Interval (NBRRHigh = longest Normal Breathing RR Interval; EHRRHigh = longest Expire-Hold RR Interval).

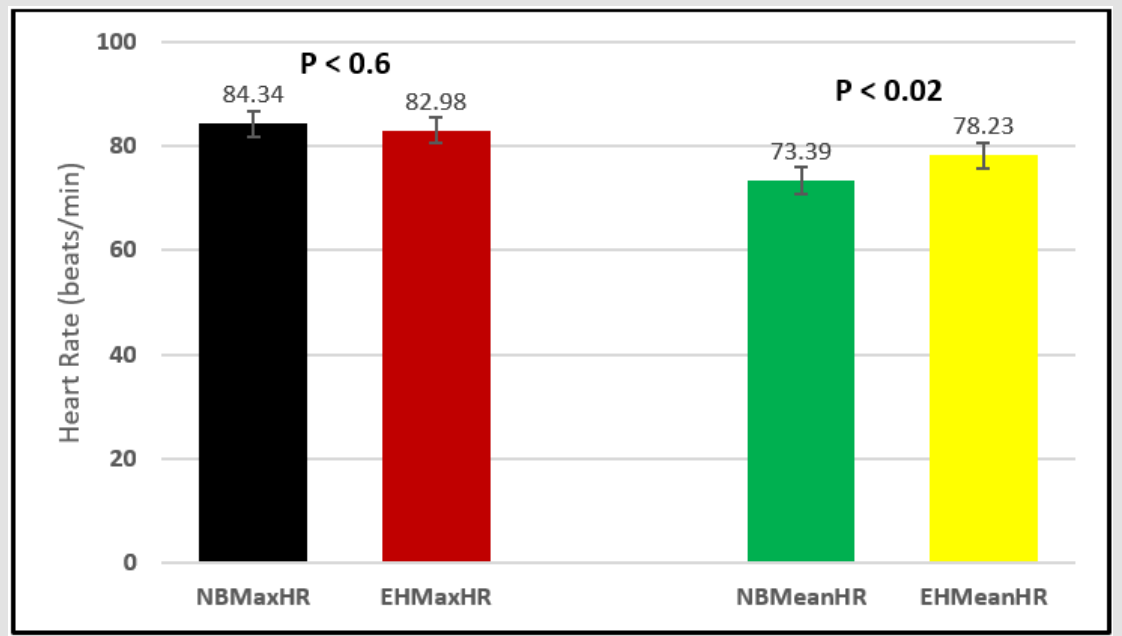

Figure 18: Subject 3 Normal Breathing Heart Rate vs. Expire-Hold Heart Rate (NBMaxHR = Normal Breathing Maximum Heart Rate; EHMaxHR = Expire-Hold Maximum Heart Rate; NBMeanHR = Normal Breathing Mean Heart Rate; EHMeanHR = Expire-Hold Mean Heart Rate).

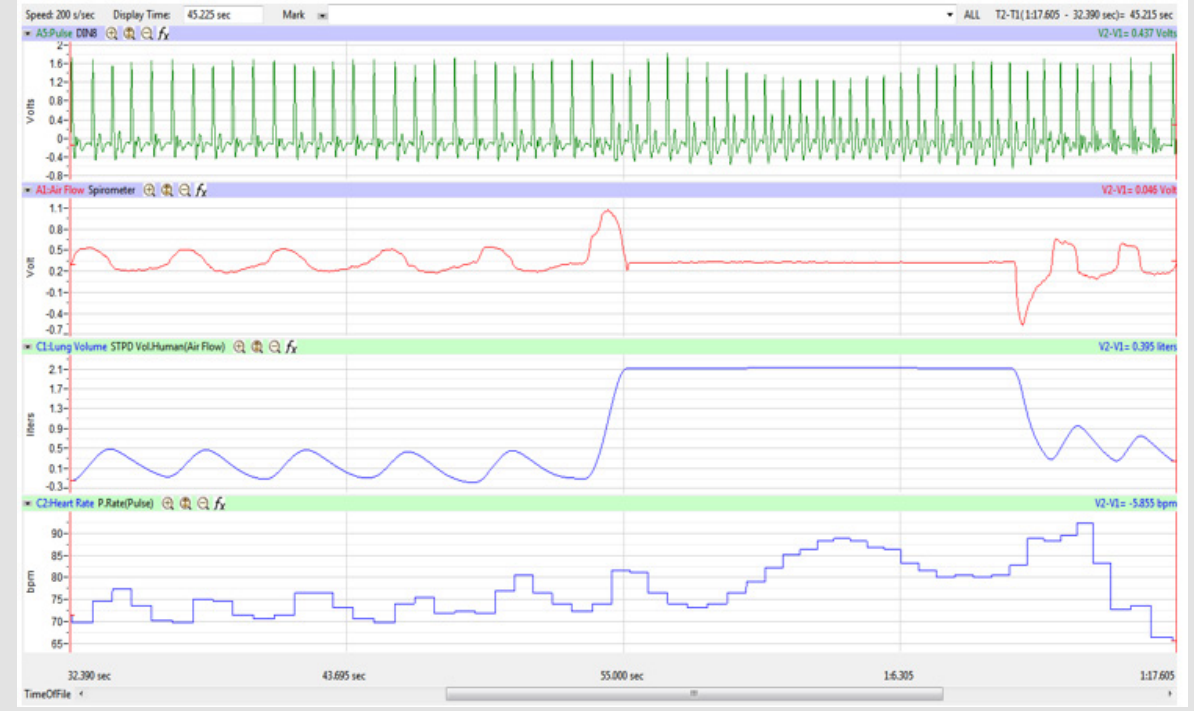

Figure 19: Subject 4 (23 Year-old, Female) - Inspire-Hold Treatment. 


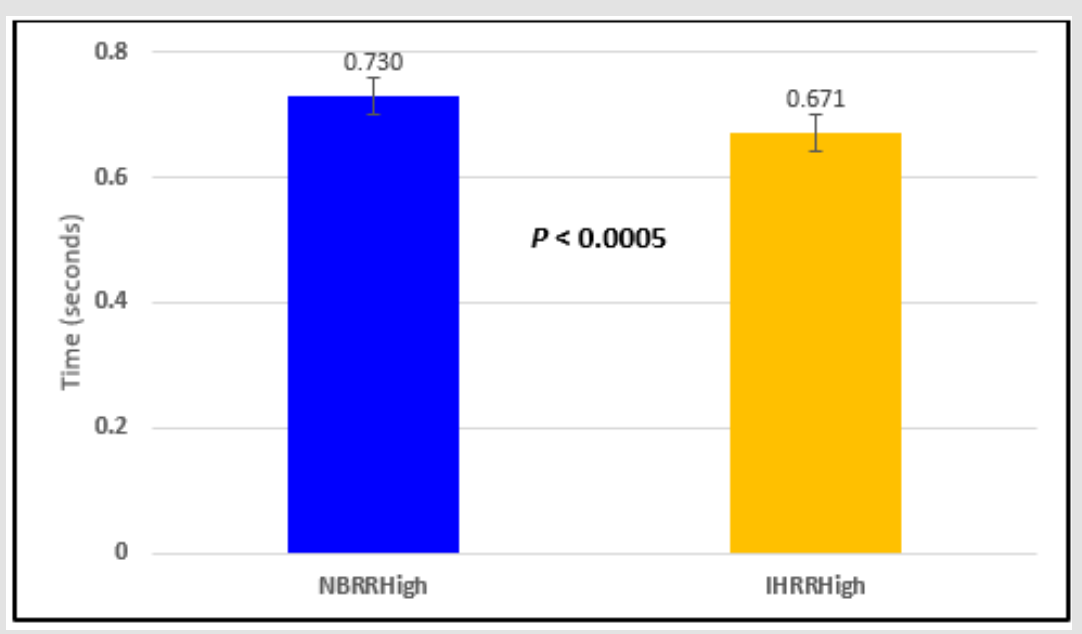

Figure 20: Subject 4 Normal Breathing RR Interval vs. Inspire-Hold RR Interval (NBRRHigh = longest Normal Breathing RR Interval; IHRRHigh = longest Inspire-Hold RR Interval).

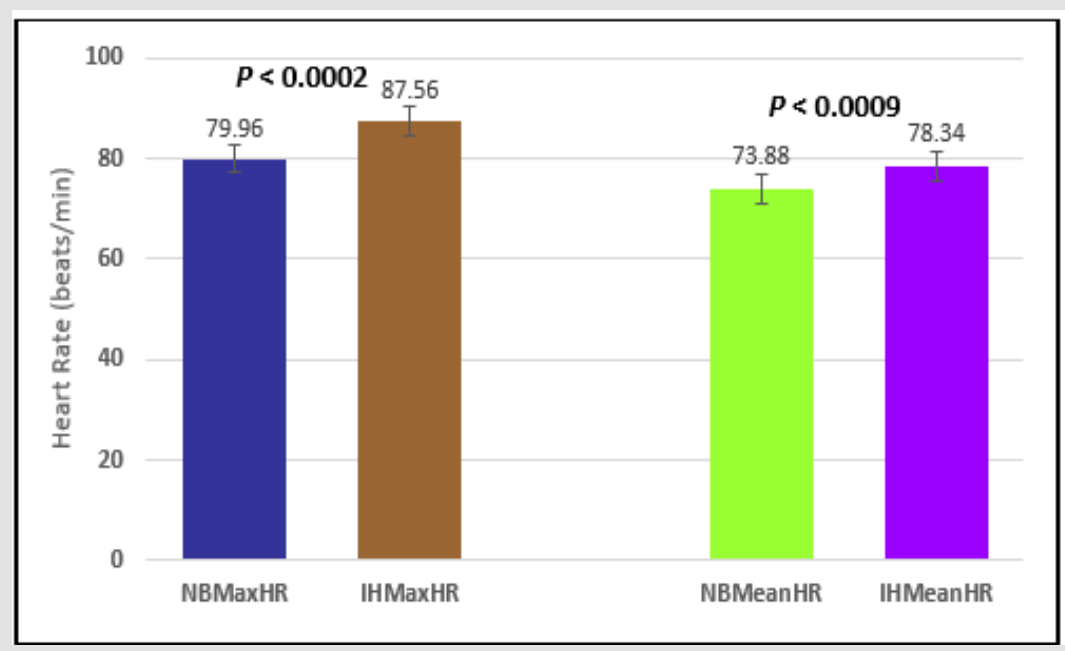

Figure 21: Subject 4 Normal Breathing Heart Rate vs. Inspire-Hold Heart Rate (NBMaxHR = Normal Breathing Maximum Heart Rate; IHMaxHR = Inspire-Hold Maximum Heart Rate; NBMeanHR = Normal Breathing Mean Heart Rate; IHMeanHR = Inspire-Hold Mean Heart Rate).

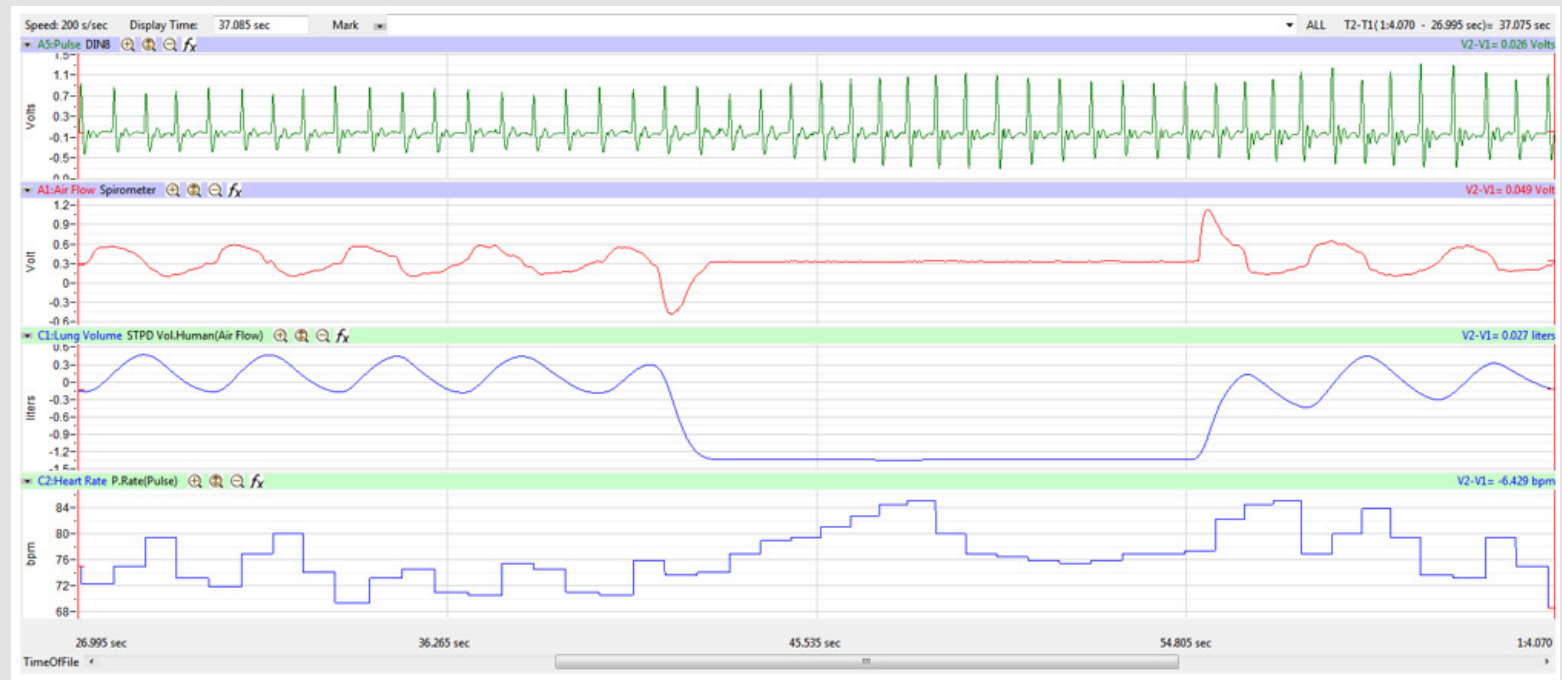

Figure 22: Subject 4 (23 Year-old, Female) - Expire-Hold Treatment. 


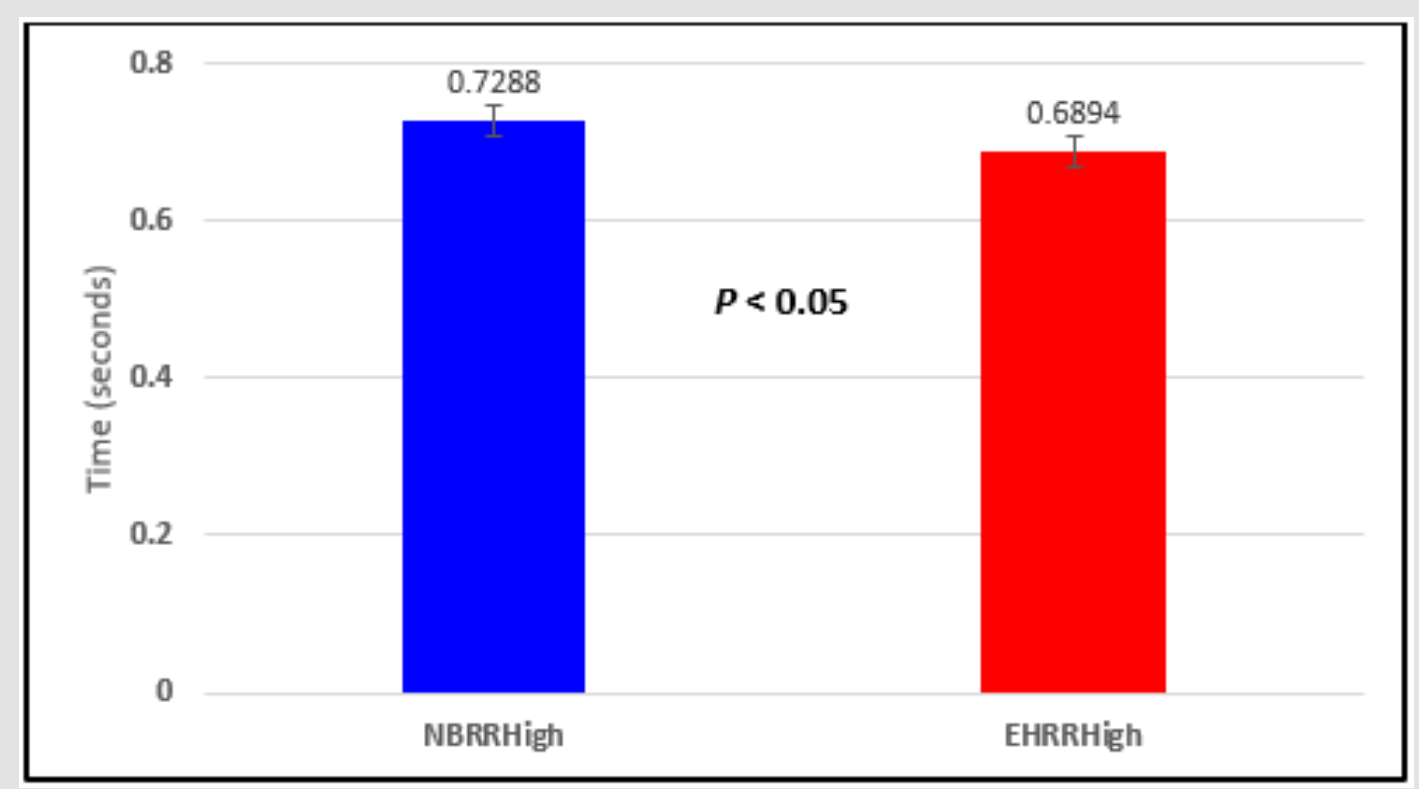

Figure 23: Subject 4 Normal Breathing RR Interval vs. Expire-Hold RR Interval (NBRRHigh = longest Normal Breathing RR Interval; EHRRHigh = longest Expire-Hold RR Interval).

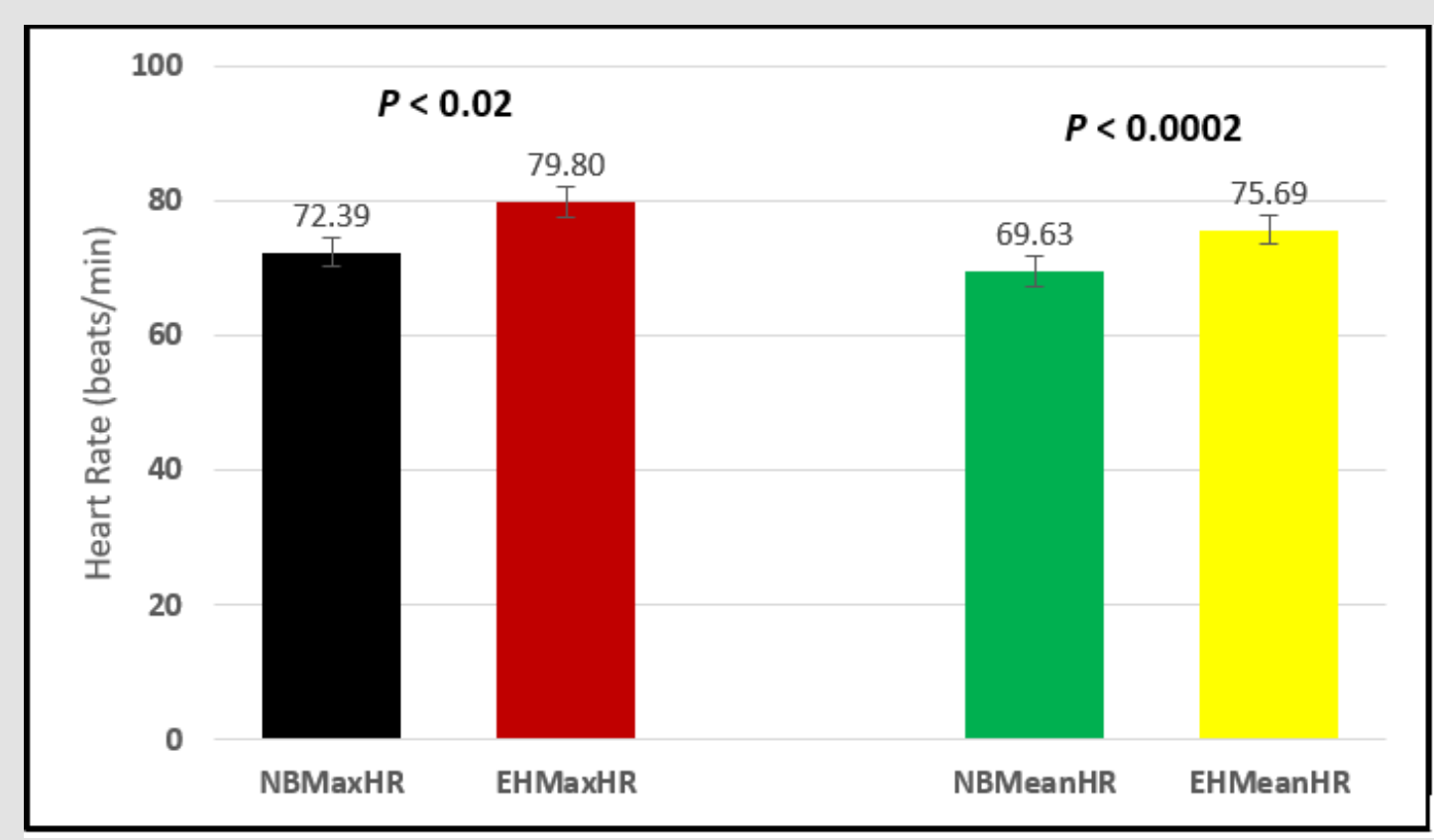

Figure 24: Subject 4 Normal Breathing Heart Rate vs. Expire-Hold Heart Rate (NBMaxHR = Normal Breathing Maximum Heart Rate; EHMaxHR = Expire-Hold Maximum Heart Rate; NBMeanHR = Normal Breathing Mean Heart Rate; EHMeanHR = Expire-Hold Mean Heart Rate).

\section{Conclusion}

This study confirmed that sustained maximum inspiration held for at least 15 seconds does indeed shorten the RR Interval which results in higher HR compared to normal breathing inspiration which confirms our first hypothesis. We observed the opposite results contrary to our second hypothesis for sustained maximum expiration held for at least 15 seconds where the RR interval was in fact shortened resulting in faster HR compared to expiration during normal breathing. Contrary to observations during normal breathing expiration and our second hypothesis, maximum expiration sustained for 15 seconds shortened the RR Interval thus also resulting in higher HR which was similar to results observed during sustained maximum inspiration. This is exactly opposite to what is observed during normal breathing expiration. Further studies of sustained maximum expiration are required to determine possible reasons behind this observation. 


\section{Acknowledgement}

We are very grateful to the Heritage University Institutional Review Board for its work in reviewing, monitoring, and regulating experimental studies involving human subjects or animal models. We would also like to thank Dr. Alexander Alexiades, our colleague in the Biology Department here at Heritage University for his assistance with statistical analysis methods.

\section{Grants}

This study was supported by funds from a Heritage University Title III STEM and Articulation federal grant entitled "Heritage University's Increasing STEM Access and Student Success for Hispanic Students".

\section{References}

1. Hayano J, Yasuma F (2003) Hypothesis: Respiratory sinus arrhythmia is an intrinsic resting function of cardiopulmonary system. Cardiovasc Res 58(1): 1-9.

2. Yasuma F, Hayano J (2004) Respiratory sinus arrhythmia: Why does the heartbeat synchronize with respiratory rhythm? Chest 125(2): 683-690.

3. Tan CO, Taylor JA (2010) Does respiratory sinus arrhythmia serve a buffering role for diastolic pressure fluctuations? Am J Physiol Heart Circ Physiol 298(5): H1492-H1498.

4. Ben-Tal A, Shamailov SS, Paton JF (2014) Central regulation of heart rate and the appearance of respiratory sinus arrhythmia: New insights from mathematical modeling. Math Biosci 255: 71-82.

5. Monfredi O, Lyashkov AE, Johnsen AB, Inada S, Schneider H, et al. (2014) Biophysical characterization of the underappreciated and important relationship between heart rate variability and heart rate. Hypertension 64(6): 1334-1343.

6. Taylor EW, Jordan D, Coote JH (1999) Central control of the cardiovascular and respiratory systems and their interactions in vertebrates. Physiol Rev 79(3): 855-916.

7. Butler PJ, Taylor EW (1983) Factors affecting the respiratory and cardiovascular responses to hypercapnic hypoxia, in mallard ducks. Respir Physiol 53(1): 109-127.

8. Taylor EW (1992) 6 Nervous control of the heart and cardiorespiratory interactions. Fish Physiol 12: 343-387.

9. Dekker JM, Schouten EG, Klootwijk P, Pool J, Swenne CA, et al. (1997) Heart rate variability from short electrocardiographic recordings predicts mortality from all causes in middle-aged and elderly men. The zutphen study. Am J Epidemiol 145(10): 899-908.

10. Ben-Tal A, Shamailov SS, Paton JF (2012) Evaluating the physiological significance of respiratory sinus arrhythmia: looking beyond ventilationperfusion efficiency. J Physiol 590(8): 1989-2008.

11. Grossman P, Taylor EW (2007) Toward understanding respiratory sinus arrhythmia: Relations to cardiac vagal tone, evolution and biobehavioral functions. Biol Psychol 74(2): 263-285.

12. Carnevali L, Sgoifo A (2014) Vagal modulation of resting heart rate in rats: The role of stress, psychosocial factors, and physical exercise. Front Physiol 5: 118.
13. Sherwood L (2016) Increased end-diastolic volume results in increased stroke volume. Human Physiology 321-322.

14. Price CJ, Crowell SE (2016) Respiratory sinus arrhythmia as a potential measure in substance use treatment--outcome studies. Addiction 111(4): 615-625.

15. Tonhajzerova I, Mestanik M, Mestanikova A, Jurko A (2016) Respiratory sinus arrhythmia as a non-invasive index of 'brain-heart' interaction in stress. Indian J Med Res 144(6): 815-822.

16. Condy EE, Scarpa A, Friedman BH (2017) Respiratory Sinus Arrhythmia Predicts Restricted Repetitive Behavior Severity. J Autism Dev Disord 47(9): 2795-2804.

17. Denver JW, Reed SF, Porges SW (2007) Methodological issues in the quantification of respiratory sinus arrhythmia. Biol Psychol 74(2): 286294.

18. Berntson GG, Bigger JT Jr, Eckberg DL, Grossman P, Kaufmann PG, et al. (1997) Heart rate variability: Origins, methods, and interpretive caveats. Psychophysiology 34(6): 623-648.

19. Ritz T, Bosquet Enlow M, Schulz SM, Kitts R, Staudenmayer J, et al. (2012) Respiratory sinus arrhythmia as an index of vagal activity during stress in infants: respiratory influences and their control. PLoS One 7(12): e52729.

20. Liang X, Evans SM, Sun Y (2017) Development of the cardiac pacemaker. Cell Mol Life Sci 74(7): 1247-1259.

21. Keith A, Flack M (1907) The form and nature of the muscular connections between the primary divisions of the vertebrate heart. J Anat Physiol 41(3): 172-189.

22. Bouairi E, Neff R, Evans C, Gold A, Andresen MC, et al. (2004) Respiratory sinus arrhythmia in freely moving and anesthetized rats. J Appl Physiol 97(4): 1431-1436.

23. Berntson GG, Cacioppo JT, Quigley KS (1993) Respiratory sinus arrhythmia: autonomic origins, physiological mechanisms, and psychophysiological implications. Psychophysiology 30(2): 183-196.

24. Allen JB, Chambers AS, Towers DN (2007) The many metrics of cardiac chronotropy: A pragmatic primer and a brief comparison of metrics. Biological Psychology 74(2): 243-262.

25. Porges SW (2007) The polyvagal perspective. Biol Psychol 74(2): 116143.

26. Peltola MJ, Mäkelä T, Paavonen EJ, Vierikko E, Saarenpää-Heikkilä O, et al. (2017) Respiratory sinus arrhythmia moderates the impact of maternal prenatal anxiety on infant negative affectivity. Dev Psychobiol 59(2): 209-216.

27. Tsypes A, James KM, Woody ML, Feurer C, Kudinova AY, et al. (2018) Resting Respiratory Sinus Arrhythmia in Suicide Attempters. Psychophysiology 55(2).

28. Sequeira V, Van der Velden J (2015) Historical perspective on heart function: The Frank-Starling Law. Biophys Rev 7(4): 421-447.

29. Borlaug BA, Reddy YNV (2017) Some Laws Were Not Made to Be Broken: When Frank-Starling Reserve Is Lost in Heart Failure. JACC Cardiovasc Imaging 10(10 Pt B): 1250-1252. 


\section{ISSN: 2574-1241}

DOI: 10.26717/BJSTR.2019.22.003732

Melvin F Simoyi. Biomed J Sci \& Tech Res

(C) (i) This work is licensed under Creative

Submission Link: https://biomedres.us/submit-manuscript.php

$\begin{array}{ll}\text { BIOMEDICAL } & \text { Assets of Publishing with us } \\ \text { RESEARCHES } & \text { - Global archiving of articles } \\ & \text { - Immediate, unrestricted online access } \\ & \text { - Rigorous Peer Review Process } \\ \end{array}$

